University of Nebraska - Lincoln

DigitalCommons@University of Nebraska - Lincoln

\title{
Laboratory bioassays of entomopathogenic fungi for control of Delia radicum (L.) larvae
}

Denny J. Bruck

USDA-ARS

Jane E. Snelling

Oregon State University

Amy J. Dreves

Oregon State University

Stefan T. Jaronski

USDA-ARS, stefan.jaronski@ars.usda.gov

Follow this and additional works at: https://digitalcommons.unl.edu/usdaarsfacpub

Part of the Agricultural Science Commons

Bruck, Denny J.; Snelling, Jane E.; Dreves, Amy J.; and Jaronski, Stefan T., "Laboratory bioassays of entomopathogenic fungi for control of Delia radicum (L.) larvae" (2005). Publications from USDA-ARS / UNL Faculty. 322.

https://digitalcommons.unl.edu/usdaarsfacpub/322

This Article is brought to you for free and open access by the U.S. Department of Agriculture: Agricultural Research Service, Lincoln, Nebraska at DigitalCommons@University of Nebraska - Lincoln. It has been accepted for inclusion in Publications from USDA-ARS / UNL Faculty by an authorized administrator of DigitalCommons@University of Nebraska - Lincoln. 


\title{
Laboratory bioassays of entomopathogenic fungi for control of Delia radicum (L.) larvae
}

\author{
Denny J. Bruck ${ }^{\mathrm{a}, *}$, Jane E. Snelling ${ }^{\mathrm{b}}$, Amy J. Dreves ${ }^{\mathrm{c}}$, Stefan T. Jaronski ${ }^{\mathrm{d}}$ \\ ${ }^{a}$ USDA-ARS, Horticultural Crops Research Laboratory, $3420 \mathrm{NW}$ Orchard Avenue, Corvallis, OR 97330, USA \\ ${ }^{\mathrm{b}}$ Bioresource Research Interdisciplinary Sciences Program, Oregon State University, Corvallis, OR 97331, USA \\ ${ }^{\mathrm{c}}$ Department of Horticulture, Oregon State University, Corvallis, OR 97331, USA \\ ${ }^{\mathrm{d}}$ USDA-ARS, Northern Plains Agricultural Research Laboratory, Sidney, MT 59270, USA
}

Received 17 December 2004; accepted 25 February 2005

Available online 7 April 2005

\begin{abstract}
Laboratory soil bioassays were performed at economic field rates for in-furrow $\left(3.85 \times 10^{6}\right.$ spores/g dry soil $)$ and broadcast $\left(3.85 \times 10^{5}\right.$ spores/g dry soil) applications with three isolates of Metarhizium anisopliae (F52, ATCC62176, and ARSEF5520) and one isolate of Beauveria bassiana (GHA). All isolates tested were infective to second instar Delia radicum (L.). The conditionally registered $M$. anisopliae isolate (F52) performed best killing an average of 85 and $72 \%$ of $D$. radicum larvae at the high and low concentration, respectively. The mean $\mathrm{LC}_{50}$ and $\mathrm{LC}_{95}$ of $\mathrm{F} 52$ against second instar D. radicum was $2.7 \times 10^{6}$ and $1.8 \times 10^{8}$ spores/g dry soil, respectively. The use of $\mathrm{F} 52$ in an integrated management program is discussed.
\end{abstract}

(C) 2005 Elsevier Inc. All rights reserved.

Keywords: Delia radicum; Metarhizium anisopliae; Beauveria bassiana, Cabbage maggot, Microbial control

The cabbage maggot, Delia radicum (L.) (Diptera: Anthomyiidae) is a serious pest of Brassicaceae crops (i.e., broccoli, cabbage, turnip, and rutabaga) in North America and Europe (Coaker and Finch, 1971; Whistlecraft et al., 1985). Females lay eggs around the base of wild and domesticated cruciferous plants. Larvae feed directly on and tunnel into the roots resulting in severe reductions in crop quality and yield (Jensen et al., 2002). In root crops such as rutabaga and turnip, larvae can render the crop unmarketable if more than slight feeding damage is evident at harvest.

Although some cultural controls such as crop rotation, row covers, and cultivation are used, current $D$. radicum control programs depend almost solely on chemical insecticides (Jyoti et al., 2001). The most commonly used pesticide for $D$. radicum control in the

\footnotetext{
${ }^{*}$ Corresponding author. Fax: +1 5417384025.

E-mail address: bruckd@onid.orst.edu (D.J. Bruck).
}

Pacific Northwest is chlorpyrifos (Lorsban), an organophosphate. Chlorpyrifos is under review by the United States Environmental Protection Agency (USEPA) as required by the Food Quality Protection Act of 1996 (Quarles, 2000). Chlorpyrifos was discontinued for household use in 2000 and is under restricted use commercially. If chlorpyrifos were no longer available for $D$. radicum control, growers would have few management alternatives.

An underutilized method for controlling $D$. radicum is the use of the entomopathogenic fungi Metarhizium anisopliae (Metchnikoff) Sorokin (Hypocreales: Clavicipitaceae) and Beauveria bassiana (Balsamo) Vuillemin (Hypocreales: Clavicipitaceae) (Vänninen et al., 1999a). Studies confirm that insect pathogenic fungi are important in agricultural systems (Klingen et al., 2002a). Both of these fungi have been evaluated for control of a variety of soil insects such as corn rootworm (Krueger and Roberts, 1997), flea beetle (Butt et al., 1997), onion maggot (Majchrowicz et al., 1990), D. radicum and Delia 
floralis (Klingen et al., 2002b; Vänninen et al., 1999a,b), as well as chinch bug (Ramoska and Todd, 1985). The objective of these studies was to determine the pathogenicity of entomopathogenic fungi against $D$. radicum.

Three isolates of $M$. anisopliae (F52, ATCC62176, and ARSEF5520) and one isolate of B. bassiana (GHA) were used in laboratory soil bioassays to determine their virulence against $D$. radicum. The isolate ARSEF5520 was originally isolated from Norwegian soils baited with D. floralis (Fallén) (Diptera: Anthomyiidae) (Klingen et al., 2002c), ATCC62176 was originally obtained from a soybean cyst nematode cyst (Carris and Glawe, 1989), F52 was provided by Earth BioSciences, Fairfield, CT, and GHA was provided as a technical grade conidial powder by Emerald BioAgriculture, Lansing, MI. ATCC62176 was produced in a biphasic culture system that simulates industrial-scale production systems (Bradley et al., 2002). Conidia were harvested by mechanical sieving through 20 and 100 mesh sieves in an ultrasonic sieve shaker (AS200, Retsch, Newton PA), with spores from the 100-mesh fraction being retained for use, and stored in the freezer at $-20^{\circ} \mathrm{C}$. The isolates ARSEF5520 and F52 were cultured on potato dextrose agar (PDA) for 14 days at $28^{\circ} \mathrm{C}$ in complete darkness. Spore viability was determined for each isolate the day prior to performing each bioassay and the spore concentration adjusted to reflect viability (Goettel and Inglis, 1997). Spore viabilities for ATCC62176 were $>75 \%$, while the spore viability of the other isolates was 90 $95 \%$.

Second instar D. radicum (Brooks, 1951) were collected from naturally infested turnip fields in Canby, Oregon. Larvae were carefully removed from infested roots in the laboratory and placed in petri dishes $(15 \times 100 \mathrm{~mm})$ lined with moistened filter paper (Whatman \#1) and turnip slices provided as food. Larvae were maintained at $4{ }^{\circ} \mathrm{C}$ for up to two days before use. Bioassays were performed using field soil [Canderly Sandy Loam (66.3:22.5:11.2, Sand:Silt:Clay)] collected from a commercial turnip field in Canby, Oregon. Before use, the soil $(1000-1500 \mathrm{~g})$ was autoclaved $\left(1.1 \mathrm{~kg} / \mathrm{cm}^{2}\right.$, $121^{\circ} \mathrm{C}$ ) for $2 \mathrm{~h}$, left overnight and autoclaved for an additional hour. The soil was then placed in a drying oven at $70^{\circ} \mathrm{C}$ for $24 \mathrm{~h}$ and stored in zip lock bags until use. Two inoculation rates were used in the bioassays. The lower rate was based on economical field application rates of entomopathogenic fungi to soil against root attacking pests (Jaronski, unpublished data). A broadcast application of $5 \times 10^{14}$ spores/hectare can result in an approximate concentration of $3.85 \times 10^{5}$ spores/g dry soil (assuming $1 \mathrm{~cm}$ of spore penetration into the soil). The upper dose was 10 -fold, to approximate a potentially very efficient spore delivery to the bases of developing plants. Spore suspensions were prepared by adding dry spores (ATCC62176 and GHA) to $10 \mathrm{ml}$ sterile $0.1 \%$ Tween 80 solution or by flooding sporulating cultures
(ARSEF5520 and F52) with $10 \mathrm{ml}$ of sterile $0.1 \%$ Tween 80 solution and agitating with a sterile loop. A hemocytometer was used to adjust spore concentrations. Twenty grams of autoclaved and oven dried soil were inoculated with each fungal isolate to achieve $3.85 \times 10^{6}$ (high concentration) and $3.85 \times 10^{5}$ (low concentration) viable spores/g dry soil at $15 \%$ final moisture $(0.00 \mathrm{MPa}$ as determined by a WP4(r) soil moisture analyzer, Decagon, Pullman, WA). To allow for uniform inoculum incorporation, spore suspensions were added in a separate, large container $(237 \mathrm{ml})$ and mixed with a sterile spatula until homogenous. The $20 \mathrm{~g}$ of soil was then placed into a $30 \mathrm{ml}$ plastic cup along with five second instar D. radicum and capped. The bioassay included an untreated control treatment of $0.1 \%$ Tween 80 solution. The treatments were arranged in a randomized complete block design and replicated four times (one cup with five larvae per replicate). The cups for each replicate were placed inside sealed $3.76 \mathrm{~L}$ zip lock bags containing moist paper towels and maintained in complete darkness at $21^{\circ} \mathrm{C}$ for 14 days. After $24 \mathrm{~h}$, a turnip slice $\left(2 \mathrm{~cm}^{2}\right)$ was added to the surface of each cup as food. Delaying the addition of the turnip slice ensured larval movement thru the soil. After 14 days, assays were evaluated for larval mortality. The bioassay was performed four times, each time with fresh spore suspensions. Three of the bioassays were performed with all four fungal isolates while GHA was not included in the fourth.

Because of high F52 efficacy and the fact that F52 is conditionally registered as a mycoinsecticide with USEPA, we performed additional bioassays to determine the $\mathrm{LC}_{50}$ and $\mathrm{LC}_{95}$ of $\mathrm{F} 52$ against second instar D. radicum in soil. Spore suspensions were prepared as described previously and soil $(70 \mathrm{~g})$ inoculated to achieve $1 \times 10^{7}, 1 \times 10^{6}, 1 \times 10^{5}$, and $1 \times 10^{4}$ viable spores/g dry soil at $15 \%$ final moisture $(0.00 \mathrm{MPa})$. Ten second instar D. radicum were added to each container $(237 \mathrm{ml})$ and capped. Containers were held under the conditions described for the single dose bioassays. The multiple dose assay was performed twice.

Abbot's formula was used to adjust for control mortality in all bioassays (Abbot, 1925). Others have found it difficult to keep $D$. radicum control mortality low in laboratory bioassays (Klingen, 2000; Vänninen et al., 1999b), however; control mortality did not exceed $10 \%$ in our studies. An arcsine transformation of the percentage larval mortality was performed to stabilize variance (Snedecor and Cochran, 1989). Data from the bioassays were analyzed using the General Linear Models Procedure (GLM) with Tukey's multiple range test used to separate means (SAS Institute, 1999). A test of homogeneity of variance was performed do detect variation between the four bioassays performed (Little and Hills, 1978). Variability was not significant between bioassays and data were combined for analysis. Data from the lethal concentration assays were analyzed using Probit 
Analysis (Sakuma, 2000). The reference probability used throughout was $P \leqslant 0.05$.

All of the fungal isolates tested were infective to second instar D. radicum at the dosages tested (Fig. 1). Because of the reduced viability of ATCC62176, the pathogenicity of this isolate may have been underestimated. Even though we quantitatively accounted for the reduced viability, the quality of these spores may have been reduced compared to the other isolates. Comparisons between isolates were also complicated because of the different spore production systems used. The high concentration $\left(3.85 \times 10^{6}\right.$ viable spores/g dry soil $)$ of all isolates consistently killed more larvae than the low concentration $\left(3.85 \times 10^{5}\right.$ viable spores/g dry soil). $D$. radicum mortality from $M$. anisopliae at the high and low concentration ranged from 85 to 48 and 72 to $28 \%$, respectively. $D$. radicum mortality from $B$. bassiana at the high and low concentration averaged 46 and 10\%, respectively. At the high concentration, F52 caused significantly higher larval mortality then ARSEF5520 and GHA (Fig. 1). At the low concentration, F52 caused significantly higher larval mortality than all other isolates. Vänninen et al. (1999b) also found M. anisopliae isolates, applied at $1 \times 10^{7}$ spores/larva to be superior to B. bassiana at infecting $D$. radicum larvae. ARSEF5520, which was originally isolated from a $D$. floralis larva in Norway and previously found to be poorly infective to $D$. floralis and not infective to late third instar D. radicum (Klingen et al., 2002c) was infective to second instar D. radicum in our studies. In our studies, $D$. radicum mortality resulting from exposure to ARSEF5520 averaged 48 and 28\% at the high and low concentration, respectively. Possible explanations for this discrepancy are an increased susceptibility of the earlier instar used in our studies, a reduction of virulence of $M$. anisopliae when the larvae were fed rutabaga (Klingen et al., 2002b), or continuous exposure of larvae to fungal inoculum in our studies compared to a $15 \mathrm{~s}$ dip in a spore suspension as performed by Klingen et al. (2002c).

The mean $\mathrm{LC}_{50}$ and $\mathrm{LC}_{95}$ of $\mathrm{F} 52$ was $2.7 \times 10^{6}$ and $1.8 \times 10^{8}$ spores/g dry soil, respectively. The parameters of the Probit analysis of F52 were very similar (Table 1). There were no significant differences in heterogeneity $(P=0.66)$ or parallelism $(P=0.47)$ between the two assays (Sakuma, 2000). The mean $\mathrm{LC}_{50}$ lies within the range of economic field rates for a tight band-over row application to soil, or an in-furrow application of entomopathogenic fungi. In-furrow application of chemical insecticides, which target the root-feeding larvae, has proven to be better suited than broadcast applications for D. radicum control (Getzin, 1985). Any of the isolates tested may have potential for use in a $D$. radicum control

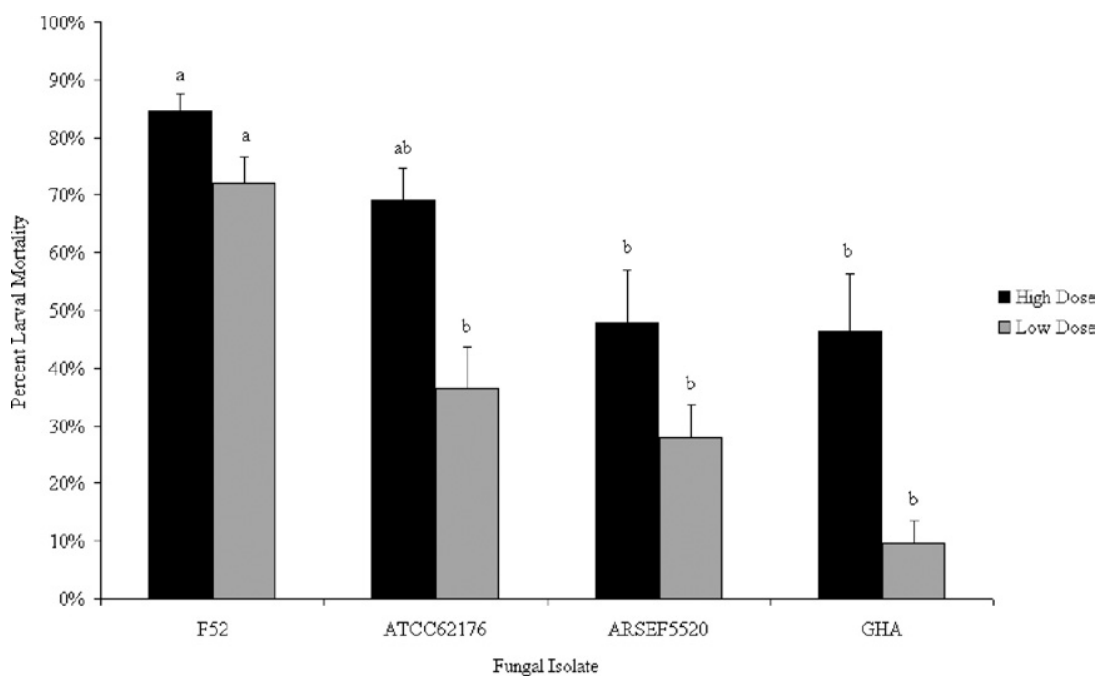

Fig. 1. Mean mortality ( $\pm 95 \%$ confidence interval) of second instar $D$. radicum after 14 days exposure to $M$. anisopliae and B. bassiana. Spore concentrations at the high and low dose were $3.85 \times 10^{6}$ and $3.85 \times 10^{5}$ viable spores/g dry soil, respectively. Isolate means from the same concentration that share the same letter are not significantly different $(P=0.05)$ (SAS Institute, 1999). ARSEF5520 was originally isolated from Norwegian soils baited with $D$. floralis (Fallén), ATCC62176 was originally obtained from a soybean cyst nematode cyst, F52 was provided by Earth BioSciences, Fairfield, CT, and GHA was provided by Emerald BioAgriculture, Lansing, MI.

Table 1

Summary of Probit analysis (Sakuma, 2000) parameters from two lethal concentration bioassays performed with the M. anisopliae isolate F52

\begin{tabular}{lllll}
\hline Bioassay & $\mathrm{LC}_{50}(95 \% \mathrm{CI})$ & Slope $( \pm \mathrm{SE})^{\mathrm{a}}$ & Heterogeneity $\chi^{2}$ & $P^{\mathrm{b}}$ \\
\hline 1 & $2.0 \times 10^{6}\left(4.1 \times 10^{5}-1.2 \times 10^{7}\right)$ & $0.77(0.27)$ & 8.19 & 0.004 \\
2 & $3.3 \times 10^{6}\left(7.5 \times 10^{5}-2.3 \times 10^{7}\right)$ & $1.05(0.38)$ & 7.80 & 0.005 \\
\hline
\end{tabular}

a Slope of the dose ( \pm standard error) response of second instar D. radicum to the M. anisopliae isolate F52.

b Probability of a greater $\chi^{2}$ value then observed (Sakuma, 2000). 
program, but considering F52's performance in the soil bioassay in conjunction with its being conditionally registered with the USEPA, this isolate provides the best opportunity for field testing and commercial use in the near future.

It is recognized that there is an increasing need for alternative methods for the control of $D$. radicum in long-season cruciferous crops. Although chlorpyrifos is used successfully on short season crops (i.e., radish), it does not persist in the soil long enough to provide sufficient control for root crops that are in the ground 90-120 days. With chlorpyrifos being the predominant management tool used, widespread resistance may also become an increasing problem in the near future. D. radicum resistance to chemical controls has been noted for over a decade (Stark, 1992) and in 2003, larvae from southwestern British Columbia were laboratory tested and found to have a 10-fold increase in chlorpyrifos resistance compared to a laboratory colony with no history of chlorpyrifos exposure (Zimmerman, unpublished data). A multi-tool approach to control D. radicum could include the use of entomopathogenic fungi. Second instar $D$. radicum can be cryptic, especially in root crops where they may penetrate entirely into the root, but they are often seen feeding at the soil root interface of root crops as well as on the surface of roots of those plants with a fibrous root system (Dreves, personal observation). Any application of an entomopathogenic fungus in the field would be targeted at the onset of egg hatch and would therefore be present in the soil to infect life stages commonly located in the soil (first and third instars, pupae) as well as second instars before they potentially penetrate the root. In our laboratory soil bioassays, M. anisopliae (F52) has shown potential as a $D$. radicum biological control agent. Although soil applications of $M$. anisopliae will likely never provide $100 \%$ control, it may be an additional tool in a D. radicum integrated management program that may also hinder resistance development to cholorpyrifos. Additional field research is needed to determine how effective F52 is at controlling $D$. radicum larvae in the field.

\section{Acknowledgments}

We thank American Type Culture Collection, USDA-ARS Collection of Entomopathogenic Fungal Cultures, Earth BioSciences and Emerald BioAgricultural Corp. for providing the isolates used in theses studies. We thank Kelly Donahue and Amanda Griffith for field and laboratory support. This article reports the results of research only. Mention of trade names or commercial products in this publication is solely for the purpose of providing specific information and does not imply recommendation or endorsement by the US Department of Agriculture.

\section{References}

Abbot, W.S., 1925. A method of computing the effectiveness of an insecticide. J. Econ. Entomol. 18, 265-267.

Bradley, C.A., Wood, P.P., Black, W.E., Kearns, R.D., Britton, J., 2002. Solid culture substrate including barley. US Patent Application Number 20020006650.

Brooks, A.R., 1951. The identification of the root maggots (Diptera: Anthomyiidae) attacking cruciferous garden crops in Canada, with notes on biology and control. Systematic Entomology, Dominion Entomological Laboratory, Saskatoon, Saskatchewan 83, 109-120.

Butt, T.M., Ibrahim, L., Clark, S.J., Beckett, A., 1997. The germination behavior of Metarhizium anisopliae on the surface of aphid and flea beetle cuticles. Mycol. Res. 99, 945-950.

Carris, L.M., Glawe, D.A., 1989. Fungi Colonizing Cysts of Heterodera glycines. Bulletin 786. University of Illinios at Urbana-Champaign, College of Agriculture.

Coaker, T., Finch, S., 1971. The cabbage root fly, Erioschia brassicae (Bouche). Rep. Natl. Veg. Res. Stn. 1970, 23-42.

Getzin, L.W., 1985. Factors influencing the persistence and effectivness of chlorpyrifos in soil. J. Econ. Entomol. 78, 412-418.

Goettel, M.S., Inglis, G.D., 1997. Fungi: hyphomycetes. In: Lacey, L.A. (Ed.), Manual of Techniques in Insect Pathology. Academic Press, San Diego, pp. 211-249.

Jensen, E., Felkl, G., Kristiansen, K., Andersen, S., 2002. Resistance to the cabbage rootfly, Delia radicum, within Brassica fruticulosa. Euphytica 124, 379-386.

Jyoti, J., Shelton, A., Earle, E., 2001. Identifying sources and mechanisms of resistance in crucifers for control of cabbage maggot (Diptera: Anthomyiidae). J. Econ. Entomol. 94, 942-949.

Klingen, I., 2000. Natural occurrence of insect pathogenic fungi and their pathogenicity on different host species with emphasis on Delia radicum and Delia floralis. Agricultural University of Norway (PhD thesis).

Klingen, I., Eilenberg, J., Meadow, R., 2002a. Effects of farming system, field margins and bait insect on the occurrence of insect pathogenic fungi in soils. Agric. Ecosyst. Environ. 91, 191-198.

Klingen, I., Hajek, A., Meadow, R., Renwick, J.A.A., 2002b. Effect of brassicaceous plants on the survival and infectivity of insect pathogenic fungi. BioControl 47, 411-425.

Klingen, I., Meadow, R., Aandal, T., 2002c. Mortality of Delia floralis, Galleria mellonella and Mamestra brassicae treated with insect pathogenic hyphomycetous fungi. J. Appl. Entomol. 126, 231-237.

Krueger, S.R., Roberts, D.W., 1997. Soil treatment with entomopathogenic fungi for corn rootworm (Diabrotica spp.) larval control. Biol. Control 9, 67-74.

Little, T.M., Hills, F.J., 1978. Agricultural Experimentation: Design and Analysis. Wiley, New York.

Majchrowicz, I., Poprawski, T.J., Robert, P.H., Maniania, N.K., 1990. Effects of entomopathogenic and opportunistic fungi on Delia antiqua (Diptera: Anthomyiidae) at relatively low humidity. Environ. Entomol. 19, 1163-1167.

Quarles, W., 2000. EPA restricts chlorpyrifos. IPM Practioner 22, 8-9.

Ramoska, W.A., Todd, T., 1985. Variation in efficacy and viability of Beauveria bassiana in the chinch bug (Hemiptera: Lygaeidae) as a result of feeding activity on selected host plants. Environ. Entomol. 19, 137-141.

Sakuma, M., 2000. PriProbit, ver. 1.63 (C). Available from James E. Throne USDA-ARS GMPRC, Manhattan, KS (http:// bru.usgmrl.ksu.edu/throne/).

SAS Institute, 1999. The SAS Statistical System, version 8. SAS Institute, Cary, NC.

Snedecor, G.W., Cochran, W.G., 1989. Statistical Methods, eighth ed. Iowa State University Press, Ames.

Stark, J.D., 1992. Combatting Cabbage Maggot Insecticide Resistance. Pacific Farmer-Stockman News, Washington State, Puyallup, pp. $7-8$. 
Vänninen, I., Hokkanen, H., Tyni-Juslin, J., 1999a. Screening of field performance of entomopathogenic fungi and nematodes against cabbage root flies (Delia radicum L. and D. floralis (Fall.); Diptera, Anthomyiidae). Acta Agric. Scand. 49, 167-183.

Vänninen, I., Hokkanen, H., Tyni-Juslin, J., 1999b. Attempts to control cabbage root flies, Delia radicum (L) and Delia floralis
(Fall.) (Dipt., Anthomyiidae), with entomopathogenic fungi: laboratory and greenhouse tests. J. Appl. Entomol. 123, 107113.

Whistlecraft, J.W., Tolman, J.H., Harris, C.R., 1985. Delia radicum. In: Singh, P., Moore, R.F. (Eds.), Handbook of Insect Rearing, vol. II. Elsevier, pp. 67-73. 